\title{
Startle and Sensorimotor Gating in Rats Lacking CCK-A Receptors
}

David Feifel, M.D., Ph.D., Kristianne Priebe, B.Sci., and Paul D. Shilling, Ph.D.

Otsuka Long Evans Tokushima Fatty (OLETF) rats lack $C C K-A$ receptors because of a genetic mutation. Previous studies have shown that $C C K-A$ receptors seem to play a role in the regulation of prepulse inhibition (PPI) of the startle reflex, an operational measure of sensorimotor gating. This study investigated baseline and drug-disrupted PPI in OLETF rats and their non-mutant counterparts, Long Evans Tokushima Otsuka (LETO) rats. Baseline PPI did not differ significantly between the two rat genotypes but OLETF rats exhibited a higher acoustic startle response compared to LETO rats. Amphetamine (2 $\mathrm{mg} / \mathrm{kg})$, and the non-competitive NMDA antagonist, dizocilpine $(0.1 \mathrm{mg} /$ $\mathrm{kg})$, disrupted PPI in LETO rats but not in the OLETF rats. Apomorphine $(0.5 \mathrm{mg} / \mathrm{kg})$ failed to disrupt PPI in both
LETO and OLETF rats, and haloperidol $(0.5 \mathrm{mg} / \mathrm{kg})$ produced a comparable facilitation of PPI in both groups. In a separate study, OLETF rats were found to be less sensitive to the locomotor stimulating effects of amphetamine. These results suggest that CCK-A receptors play a significant role in the behavioral effects of amphetamine and dizocilpine. The PPI response of OLETF rats to amphetamine and dizocilpine is similar to normal rats pretreated with atypical antipsychotics, suggesting that CCK-A receptors may play an important role in the restoration of drug-disrupted PPI by antipsychotics.

[Neuropsychopharmacology 24:663-670, 2001]

(C) 2001 American College of Neuropsychopharmacology. Published by Elsevier Science Inc.
KEY WORDS: Amphetamine; Apomorphine; Dizocilpine; Haloperidol; OLETF; LETO; Schizophrenia; Prepulse inhibition; Startle; Locomotor activity; Cholecystokinin; CCK; CCK-A

Cholecystokinin (CCK), a gut-brain peptide, has been implicated in the modulation of mesolimbic dopamine transmission. CCK coexists with dopamine in a large proportion of mesolimbic neurons that terminate in the medial-posterior nucleus accumbens (mpNAC) (Hokfelt et al. 1980). CCK co-localized in mesolimbic dopamine cells appears to potentiate dopamine transmission

From the Department of Psychiatry, University of California, San Diego, La Jolla, CA

Address correspondence to: David Feifel, M.D., Ph.D., Department of Psychiatry, University of California, San Diego, 9500 Gilman Dr., La Jolla, CA 92093-8218. Tel.: (619) 543-2827; Fax: (619) 5433738; E-mail: dfeifel@ucsd.edu

Received April 18, 2000; revised October 18, 2000; accepted October 31,2000 via CCK-A receptors in the mpNAC (Crawley 1991). CCK in the periphery has also been shown to regulate mesolimbic function by what appears to be a presynaptic mechanism of action mediated by peripheral CCK-A receptors (Kariya et al. 1994; Kihara et al. 1993). Because of its ability to regulate mesolimbic function, the CCKA system could contribute to mechanism underlying psychiatric disorders such as schizophrenia.

Otsuka Long Evans Tokushima Fatty (OLETF) rats lack CCK-A receptors because of a spontaneous mutation (Funakoshi et al. 1995). These rats have been studied extensively as a model to understand the metabolic role of peripheral CCK as they have a tendency to demonstrate diabetes-like changes after 18 weeks of age (Otsuki et al. 1995). OLETF rats represent a potentially useful model to investigate the role of the endogenous CCK-A system in the regulation of mesolimbic dopamine function. A previous study found that OLETF rats exhibited decreased spontaneous locomotor activity relative to Long Evans Tokushimo Otsuka (LETO) rats, 
their control counterparts, and the authors suggested that this difference may be the result of perturbations in basal dopamine regulation in OLETF rats (Kobayashi et al. 1996). We previously reported that amphetamineinduced early gene expression, as measured by zif 268 mRNA expression in the NAC, did not differ between LETO and OLETF rats (Shilling et al. 2000).

To further examine the role of the CCK-A receptor in the regulation of mesolimbic dopamine function, this study investigated prepulse inhibition (PPI) in OLETF and LETO rats. PPI is the normal suppression of the startle response when the intense startling stimulus (pulse) is preceded immediately (50-200 msecs) by a much weaker, non-startling stimulus (prepulse) such as an auditory "click". PPI was studied because it is an operational measure of sensorimotor gating and the basis of an important animal model of information processing deficits associated with schizophrenia (Swerdlow et al. 1994). PPI is deficient in unmedicated patients with schizophrenia and homologous deficits can be produced in rats by administering them dopamine agonists such as apomorphine or amphetamine, or non-competitive NMDA antagonists such as phencyclidine (PCP) or dizocilpine (MK801) (Braff and Geyer 1990). Drugs that reverse drug-induced disruption of PPI are strong candidates for clinically effective antipsychotics (Swerdlow et al. 1994). Drug-disrupted PPI therefore appears to represent an animal model of deficient sensorimotor gating that exhibits good face, construct, and predictive validity for sensorimotor gating deficits measured in patients with schizophrenia (Swerdlow et al. 1994). Previous results from our laboratory suggest that PPI may have greater predictive validity for CCKs putative psychotropic effects than other behavioral measures of mesolimbic dopamine function, such as stimulant-induced hyperlocomotion (Feifel et al. 1999a). Furthermore, we demonstrated that CCK administered centrally and peripherally can modulate dopamine agonist-induced disruption of PPI by mechanism likely to involve CCK-A receptors (Feifel and Swerdlow 1997; Feifel et al. 1999a).

In the current study we compared baseline PPI in OLETF and LETO rats as well as the relative response of both these rat genotypes to a direct (apomorphine) and indirect (amphetamine) dopamine agonist both of which are known to disrupt PPI by facilitation of mesolimbic dopamine transmission. We also tested the effects of haloperidol on PPI of both genotypes, since it has been shown to facilitate PPI in rats (Depoortere et al. 1997; Johansson et al. 1995). To determine the pharmacological specificity of any differences in dopamine agonist-induced PPI disruption between OLETF and LETO rats, we also tested the effects of dizocilpine (MK-801), a non-competitive NMDA antagonist that disrupts PPI by a mechanism that does not involve simple enhancement of dopamine transmission (Keith et al. 1991). To assess the behavioral specificity of any PPI differences in OLETF versus LETO rats, we also compared the effects of amphetamine on locomotor activity of OLETF and LETO rats. Based upon evidence of CCKA-dopamine interaction, we predicted that PPI in OLETF rats would differ significantly in the magnitude of their PPI response to amphetamine and apomorphine but not dizocilpine.

\section{METHODS}

Forty-two male OLETF and LETO rats were obtained (Tokushima Research Institute, Otsuka Pharmaceutical Co., Ltd.) at five weeks of age. After at least 14 days of habituation to home cages, rats were tested. On the test each rat received a subcutaneous (SC) injection of saline, amphetamine $(2 \mathrm{mg} / \mathrm{kg})$, apomorphine $(0.5 \mathrm{mg} /$ $\mathrm{kg})$, dizocilpine $(0.1 \mathrm{mg} / \mathrm{kg})$, or haloperidol $(0.5 \mathrm{mg} /$ $\mathrm{kg}$ ). Approximately ten minutes after SC injections, animals were placed in startle chambers for testing. Startle chambers (SR-LAB, San Diego Instruments, San Diego, CA) consisted of a Plexiglas cylinder $8.2 \mathrm{~cm}$ in diameter resting on a $12.5 \times 25.5 \mathrm{~cm}$ Plexiglas frame within a ventilated enclosure housed in a sound-attenuated room exposed to a $65 \mathrm{~dB}$ background noise. Following a 5-min acclimation period, rats received acoustic stimuli consisting of a $120 \mathrm{~dB}$ pulse by itself (pulse-alone) or a $120 \mathrm{~dB}$ pulse preceded by prepulses that were 4,8 , or 12 $\mathrm{dB}$ above background noise, presented $100 \mathrm{msec}$ before the pulse. During each session each stimuli type was presented 7 times in a pseudorandomized order. A piezoelectric accelerometer mounted below the Plexiglas frame detected and transduced the motion within the cylinder.

Prepulse inhibition was calculated as a percentage of the peak pulse-alone startle amplitude using the following formula: $[1-$ (startle amplitude following prepulsepulse pair/startle amplitude following pulse-only)] $\times$ 100. Analysis of data was then carried out using a series of three-factor, repeated measures ANOVA for each drug treatment in which rat genotype and drug were between subject factors and prepulse intensity was a within subject factor. Significant factor results from the ANOVA were followed up using Tukey post-hoc comparisons.

A separate group of OLETF and LETO rats were habituated to cages equipped with eight horizontal photobeam sensors designed to record locomotor activity (San Diego Instruments, San Diego, CA) for $30 \mathrm{~min}$. Following this habituation period, half the OLETF and half the LETO rats were administered amphetamine $(2 \mathrm{mg} /$ $\mathrm{kg}$ ) SC, while the rest of the rats were administered SC saline. After SC injections, animals were replaced in locomotor cages, and locomotor activity was recorded for the following $30 \mathrm{~min}$. One week later, animals were tested again. In this session, animals that received amphetamine on the first test session received saline and 


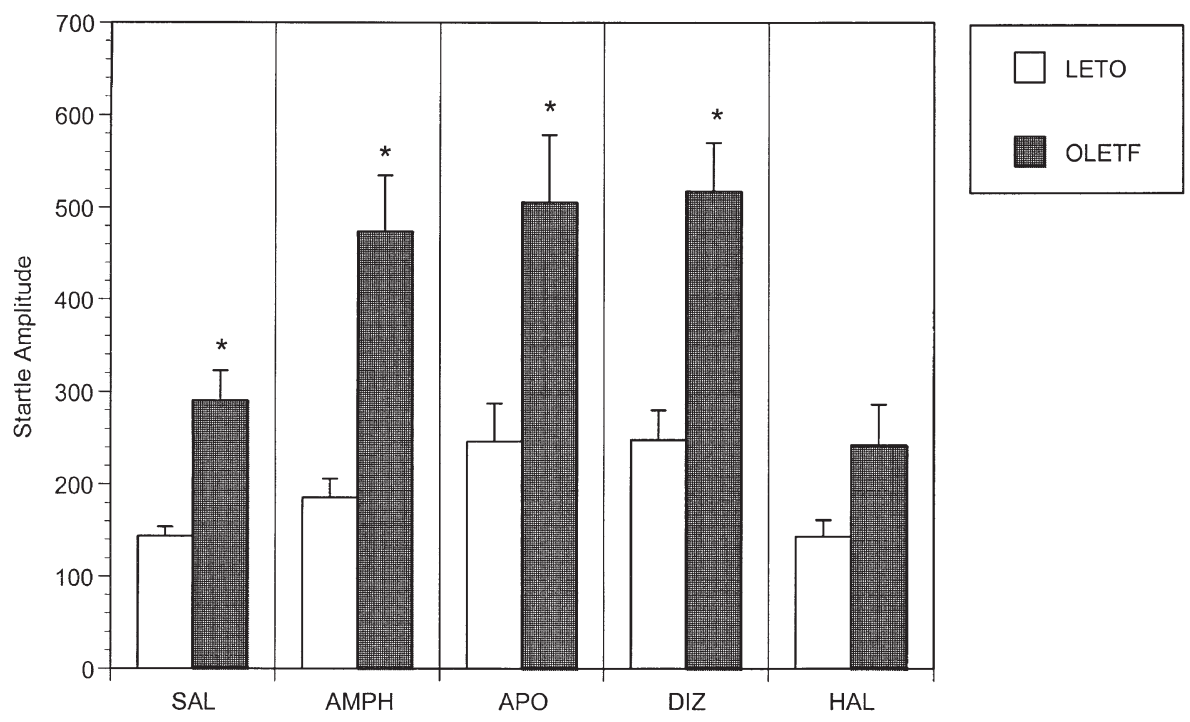

Figure 1. Mean startle amplitude $( \pm$ SEM) in rats devoid of CCK-A receptors (OLETF) and their control counterparts (LETO) following SC injection of saline, $2 \mathrm{mg} / \mathrm{kg}$ amphetamine, $0.5 \mathrm{mg} / \mathrm{kg}$ apomorphine, $0.1 \mathrm{mg} / \mathrm{kg}$ dizocilpine, or $0.5 \mathrm{mg} / \mathrm{kg}$ haloperidol. *Significantly different $(p<.05)$ from same drug-LETO group. vice versa. Total beam and crossover activity counts were analyzed using a two factor ANOVA (amphetamine $\times$ genotype). Significant factor results from the ANOVA were followed up using Tukey post-hoc comparisons. Similar results were obtained for both crossover and total activity counts and therefore total activity counts are presented here.

\section{RESULTS}

\section{ASR}

OLETF rats had higher baseline ASR than LETO rats, revealed by a main effect of genotype $[\mathrm{F}(1,84)=59.1, p<$ .001]. There was also a main effect of drug on ASR $[\mathrm{F}(4,84)=8.29, p<.001]$ and the data reveal that amphetamine, apomorphine, and dizocilpine, but not ha- loperidol, significantly increased ASR compared with saline. There was not a significant drug $\times$ genotype interaction effect although the data suggest a notable tendency for greater facilitation of ASR by amphetamine, apomorphine, and dizocilpine in OLETF rats (Figure 1).

\section{Percent PPI}

There was a main effect of prepulse intensity $[\mathrm{F}(2,168)=$ $80.65, p<.001)$, expressed as the well established ability of stronger prepulse intensities to produce greater PPI. There was a significant main effect of genotype $[\mathrm{F}(1,84)=$ $10.93, p<.001)$, a main effect of drug $[\mathrm{F}(4,84)=10.93$, $p<.001)$ and a significant drug $x$ genotype interaction $[\mathrm{F}(4,84)=2.5, p<.05)$. Separate one factor (genotype) ANOVAs for each drug treatment revealed a significant effect of genotype for amphetamine $[\mathrm{F}(1,24)=9.75, p<$

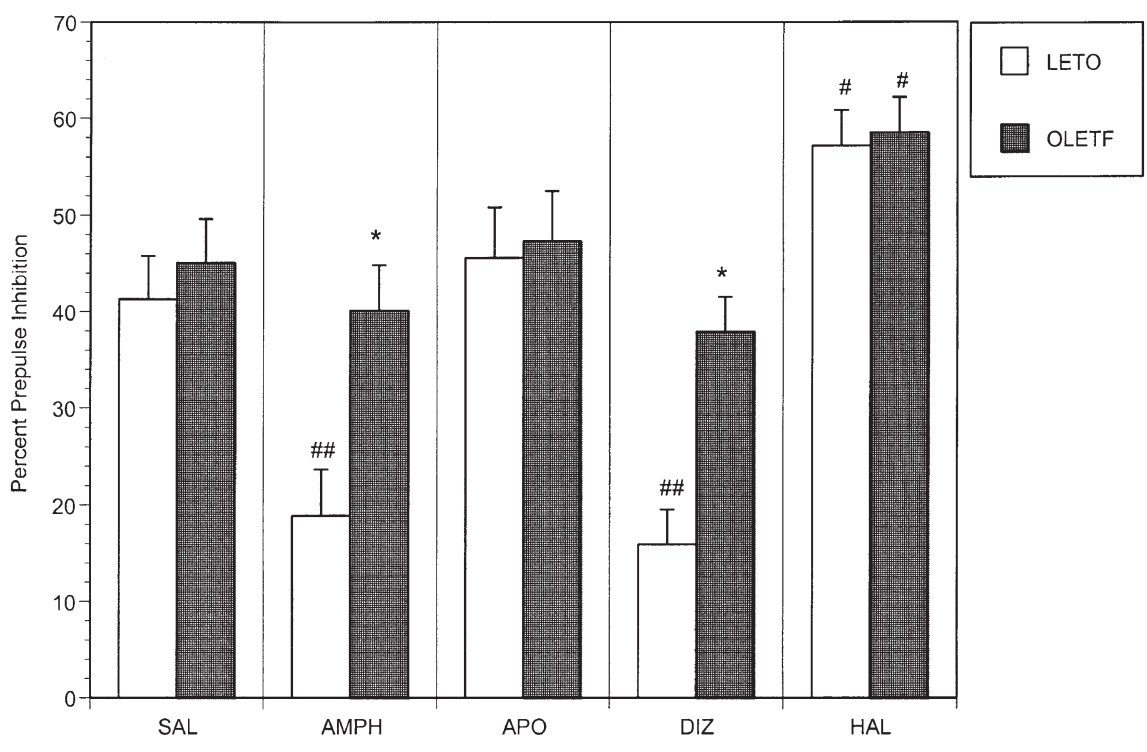

Figure 2. Mean percent PPI $( \pm$ SEM $)$ in rats devoid of CCK-A receptors (OLETF) and their control counterparts (LETO) following SC injection of saline, $2 \mathrm{mg} / \mathrm{kg}$ amphetamine, 0.5 $\mathrm{mg} / \mathrm{kg}$ apomorphine, $0.1 \mathrm{mg} / \mathrm{kg}$ dizocilpine, or $0.5 \mathrm{mg} / \mathrm{kg}$ haloperidol. *significantly different $(p<.01)$ from the same drug-LETO group. Significantly different from the salinetreated rats of the same strain: $\# p<$ $.05, \# \# p<.01$. 
Table 1. Mean (SD) Startle Amplitude in LETO and OLETF Rats Following 120 dB Presented Alone or 100 msecs Following a 4, 8, or $12 \mathrm{~dB}$ Above Background Pre-stimulus

\begin{tabular}{llllcrr}
\hline Drug & Strain & Pulse-alone & Pre(4) + Pulse & Pre(8) + Pulse & Pre(12) + Pulse & Pre(all) + Pulse \\
\hline Saline & LETO & $144.1(35.7)$ & $101.3(45.6)$ & $84.8(28.5)$ & $65.3(29.1)$ & $83.9(31.6)$ \\
& OLETF & $290.4(119.1)$ & $193.7(124.5)$ & $155.1(85.5)$ & $136.3(77.5)$ & $161.7(91.3)$ \\
Amphetamine & LETO & $185.9(72.5)$ & $169.1(61.3)$ & $146.6(54.0)$ & $122.5(56.8)$ & $146.1(54.3)$ \\
& OLETF & $474.5(220.3)$ & $303.1(125.9)$ & $264.9(113)$ & $223.7(97.7)$ & $263.9(106.7)$ \\
Apomorphine & LETO & $246.5(39.6)$ & $151.9(26.8)$ & $145.7(35.2)$ & $107.9(25.8)$ & $135.2(28.7)$ \\
& OLETF & $506.3(70.4)$ & $328.5(56.0)$ & $252.9(47.2)$ & $244.1(43.2)$ & $275.2(47.2)$ \\
Dizocilpine & LETO & $248.3(109.3)$ & $210.6(98.9)$ & $230.3(147.3)$ & $200.9(122.7)$ & $213.9(121.9)$ \\
\multirow{2}{*}{ Haloperidol } & OLETF & $518.1(146.4)$ & $332.3(85.8)$ & $342.2(125.6)$ & $285.4(108.1)$ & $319.9(97.8)$ \\
& LETO & $143.5(18.5)$ & $89.2(16.9)$ & $67.0(11.5)$ & $33.3(6.9)$ & $63.2(10.8)$ \\
& OLETF & $242.1(44.6)$ & $124.1(26.5)$ & $109.3(26.2)$ & $81.5(21.3)$ & $105.0(24.5)$ \\
\hline
\end{tabular}

$.01)$ and dizocilpine $[\mathrm{F}(1,14)=10.07, p<.01)$ but not for saline, apomorphine, or haloperidol (Figure 2).

As expected, amphetamine and dizocilpine significantly disrupted PPI and haloperidol facilitated PPI in LETO rats. Apomorphine had no significant effect on PPI in LETO rats. The data reveal that OLETF rats did not differ significantly from LETO rats in baseline PPI. However, OLETF rats were much less sensitive to the PPI disrupting effects of amphetamine and dizocilpine compared to LETO rats, as evidenced by the fact that each of these drugs significantly reduced PPI in LETO rats but had no significant effect on the PPI exhibited by OLETF rats (Figure 2). Table 1 presents the absolute startle data in response to startling stimuli with and without prepulses.

Because genotype-based differences were found in both PPI and in ASR, further statistical exploration was performed to investigate whether the PPI differences were related to differences in ASR. A Spearman correlation revealed no significant correlation between ASR and percent PPI among individual rats of either group $(\mathrm{r}=0.095$, NS).

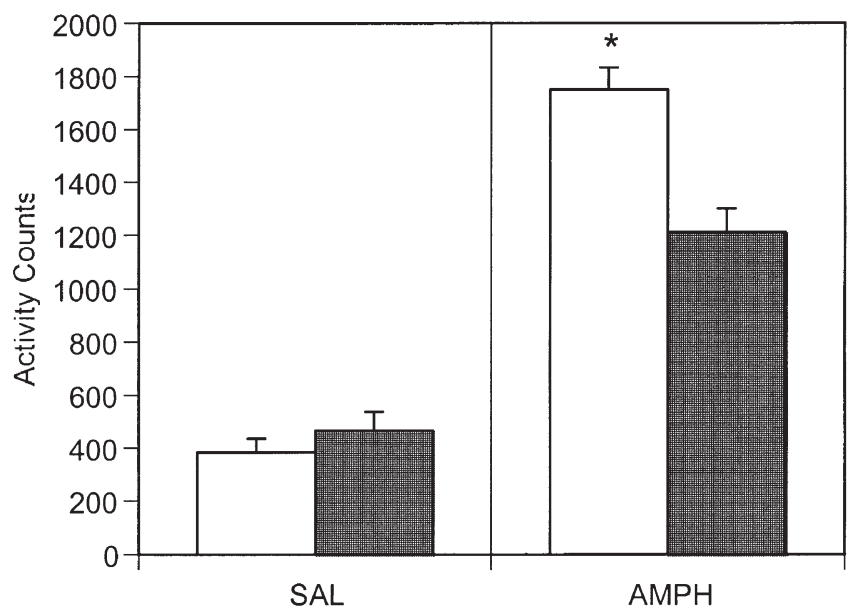

\section{DISCUSSION}

OLETF rats did not exhibit significantly different baseline PPI or locomotion compared with their control counterparts, suggesting that CCK-A receptors do not play an important role in regulation of baseline PPI or locomotion. Since both PPI and locomotor activity is regulated by mesolimbic dopamine (Swerdlow et al.

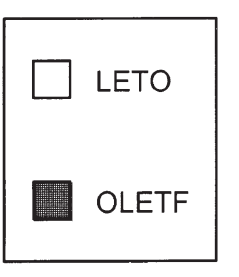

Figure 3. Locomotor activity ( \pm SEM) exhibited by OLETF and LETO rats 30 min after SC injection of $2 \mathrm{mg} / \mathrm{kg}$ amphetamine (AMPH) or saline (SAL). *significantly different $(p<.01)$ than OLETF-AMPH rats. 
1990a; Wan et al. 1995), these results suggest that CCKA receptors probably do not significantly regulate basal mesolimbic dopamine function. This stands in contrast to a previous report by Kobayashi et al. (1996), which found that OLETF rats had significantly less spontaneous locomotor activity compared to LETO rats. The basis for these contradictory findings is unclear but may be the result of methodological differences because the study by Kobayashi et al., but not the current one, used an open field apparatus.

As expected, amphetamine and dizocilpine produced a significant disruption of PPI in LETO rats. Surprisingly, apomorphine did not disrupt PPI in LETO rats. Apomorphine's lack of effect on PPI is not likely due to a methodological failure related to the drug or drug administration because apomorphine did significantly facilitate ASR by a magnitude which was comparable to that produced by amphetamine and dizocilpine. Several reports have documented strain differences in PPI response to apomorphine with some strains exhibiting no disruption of PPI after administration of apomorphine (Kinney et al. 1999; Rigdon 1990; Swerdlow et al. 2000). For example, Rigdon (1990) found apomorphine-induced facilitation of startle but had no effect on PPI in a strain of rat. This is similar to the startle effects we observed following administration of apomorphine on LETO rats. We have found a similar insensitivity to apomorphine-induced PPI effects, but not ASR, in non-LET0, Long Evans rats (unpublished data). Regardless of the underlying mechanism, the lack of apomorphine-induced disruption of PPI in LETO rats precludes a meaningful interpretation of the role of CCK-A receptors in this effect.

That OLETF rats were less sensitive to the PPI effects of amphetamine is generally consistent with our prediction, which was based upon previous work suggesting that CCK-A receptors in the NAC potentiate mesolimbic dopamine transmission. However, the finding that amphetamine's PPI disrupting effects were totally blocked in OLETF rats, rather than being attenuated, is surprising because CCK-A receptors are believed to play only a modulatory role in dopamine function. OLETF rats were also less sensitive to the locomotor activating effects of amphetamine. However, unlike the case with PPI, OLETF rats were not completely insensitive to amphetamine's locomotor effects since OLETF rats displayed a significant increase in amphetamine-induced locomotor stimulation. This finding is more compatible with a loss of pro-dopamine, CCK-A receptors in the brain. It is possible that higher doses of amphetamine would reveal partial disruption of PPI in OLETF rats. It is also possible that CCK-A receptors play somewhat distinct roles in regards to PPI and locomotor behavior such that they potentiate dopamine-stimulated locomotor behavior and play a more permissive role in regards to dopamineinduced disruption of PPI.
That dizocilpine-induced disruption of PPI was also blocked in OLETF rats was not predicted. PPI disruption by dizocilpine is not the result of acute facilitation of mesolimbic dopamine transmission as evidenced by the finding that this effect is not reversed by acute administration of haloperidol (Keith et al. 1991). The mechanism by which OLETF rats are rendered insensitive to dizocilpine-induced disruption in PPI is not clear. Whereas all antipsychotics tested can block amphetamine-induced disruption of PPI, only some drugs can block the PPI effects of non-competitive NMDA antagonists. These include several atypical antipsychotics (Bakshi and Geyer, 1995; Bakshi et al. 1994; Swerdlow et al. 1996), serotonin (Varty and Higgins 1995), alphaadrenergic antagonists (Bakshi and Geyer 1997), nitric oxide synthetase inhibitors (Johansson et al. 1997), and some neuropeptides (Feifel and Reza 1999; Feifel et al. 1999b). Thus, OLETF rats may have alterations in one or more of these systems making them less sensitive to the PPI disrupting effects of non-competitive NMDA antagonists.

There is evidence that CCK receptors in the anterior NAC regulate the behavioral effects produced by NMDA antagonists, but these receptors appear to be of the CCK-B type (Popoli et al. 1995). It is possible that in response to the lack of CCK-A receptors, OLETF rats overexpress CCK-B receptors in the NAC, which may in turn play a role in regulating PPI. However, arguing against overexpression of CCK-B receptors is the finding that there is no evidence of differences in brain CCK-B receptor mRNA expression in OLETF rats (Kobayashi et al. 1996). Taken together with the fact that PPI in OLETF rats were not affected by amphetamine, the lack of responsitivity to dizocilpine-induced PPI disruption in OLETF rats suggests that the absence of CCK-A receptors may alter PPI circuits rendering them unresponsive to disruption by drugs. Further studies examining the response of OLETF rats to other drugs that disrupt PPI, for example, the serotonin receptor antagonist, DOI (2,5-dimethoxy-4-iodoamphetamine) (Sipes and Geyer 1994) or the alpha-1 agonist, prazosin (Bakshi and Geyer 1997), would be helpful to elucidate this issue.

Haloperidol significantly facilitated PPI in both LETO and OLETF rats by a similar magnitude, suggesting that CCK-A receptors likely do not play a role in this phenomenon. The precise mechanism underlying PPI facilitation by haloperidol and other antipsychotics is not known. There is evidence that it is not mediated simply by D2 receptor antagonism since certain drugs with strong D2 affinity, such as risperidone and NCQ298, do not facilitate PPI (Johansson et al. 1995). Depoortere et al. (1997) suggest that alpha-1 adrenoreceptors may play an important role in antipsychotic-induced facilitation of PPI. The lack of differences in PPI response to haloperidol between LETO and OLETF rats suggests 
that the lack of sensitivity to PPI disruption exhibited by OLETF rats does not generalize to drug induced facilitation of PPI.

The finding that OLETF rats had significantly higher baseline ASR than LETO rats is somewhat surprising since CCK-A receptors have not been strongly implicated in the regulation of the ASR. CCK administered into the pontine reticular nucleus, an obligatory relay for the ASR, facilitates ASR (Fendt et al. 1995), but this effect is likely mediated by CCK-B receptors (Fendt et al. 1995). The ASR is considered an operational measure of anxiety (Walker and Davis 1997). While CCK has been implicated as an anxiogenic, this effect is also thought to be mediated by CCK-B receptors (van Megen et al. 1996). Even so, treatment with a CCK-B antagonist has no effect on baseline ASR (Josselyn et al. 1995). One possible simple explanation for the ASR differences may result from the fact that OLETF rats were significantly heavier (average $450 \mathrm{~g}$ ) compared to the LETO (average $362 \mathrm{~g}$ ), a well-established finding. Since the measurement of startle response is sensitive to weight displaced, these weight differences may have contributed to the stronger startle amplitude measured for OLETF rats.

The findings in this study that amphetamine, apomorphine, and dizocilpine increase ASR is consistent with previous reports (Swerdlow et al. 1990b; Zhang et al. 1997). The baseline and drug-induced ASR differences between OLETF and LETO rats may have contributed to the PPI differences observed in these two groups of rats. However, several lines of evidence argue against this. First, measuring each animal's PPI as a percentage of its own ASR minimizes the influence of changes in startle reactivity on PPI (Swerdlow et al. 1994). Furthermore, ASR and PPI are highly dissociable. Converging evidence suggests that the startle reflex amplitude and prepulse inhibition, determined usually as percent PPI, are independent phenomena. Evidence in support of this comes from studies that have found manipulations which alter ASR but not PPI (Rigdon 1990; Swerdlow et al. 1986), PPI but not ASR (Furuya et al. 1999; Rigdon 1990; Swerdlow et al. 1990b), ASR and PPI in the same direction (Acri et al. 1995), and ASR and PPI in opposite directions (al-Amin and Schwarzkopf 1996). Furthermore, studies have found that individual startle amplitude and PPI are not necessarily correlated (Feifel 1999; Paylor and Crawley 1997), although one study did find a positive correlation (Logue et al. 1997). Evidence that ASR and PPI are dissociable is also apparent from the results of this study. For example, despite the fact that baseline ASR differed significantly between OLETF and LETO rats, baseline PPI did not significantly differ. Finally, we also found that individual ASR did not significantly correlate with PPI.

Relevant to the current findings are previous findings that acute administration of devazepide, a selective CCK-A antagonist, has no effect on baseline or dopa- mine-induced changes in locomotor activity (Crawley 1992). Preliminary data from our laboratory reveals a similar inability of devazepide to modulate baseline or amphetamine-induced changes in ASR and PPI. Taken together with the current findings, this suggests that the differences seen in the PPI and locomotion of OLETF versus LETO rats are not attributable to a straightforward disruption in CCK-Aergic transmission. Several possible explanations exist for the disparity between the findings in OLETF versus devazepide-treated normal rats. It is possible that the disparity is due to the chronic nature of the CCK-Aergic deficit in OLETF rats compared with the acute disruption in devazepide-treated rats. In this scenario, chronic treatment with devazepide might be expected to induce an OLETF-like reduced sensitivity to drug-induced disruption of PPI.

Beyond the simple difference in duration of the CCK-Aergic disruption produced genetically in OLETF rats versus pharmacologically by a CCK-A antagonist, a more important distinction may be related to the developmental timing of the deficits. Unlike devazepidetreated rats, the deficits in CCK-Aergic function in OLETF rats are congenital. The lack of CCK-A receptors during critical stages of neural development in OLETF rats may invoke compensatory effects in neural substrates associated with sensorimotor gating which result in PPI that is overtly normal but which is less sensitive to disruption by certain drugs.

The disparity between the PPI findings in OLETF rats versus devazepide treated rats may also result from differences not directly related to CCK-A function. That is, the genetic mutation responsible for CCKA receptor deficits may also impart other changes in OLETF rats that are not induced by devazepide; that may be important in regards to PPI regulation by dopaminergic and glutamatergic systems. For example, as a result of abnormal CCK-A function, OLETF rats may develop compensatory changes in DA receptors. Measurement of DA receptor levels in OLETF rats would be an important area of further research.

PPI disruptions by dopamine agonists and by noncompetitive NMDA antagonists represent important models of the dopamine and glutamate hypothesis of schizophrenia, respectively (Swerdlow and Geyer 1998). The ability of a drug to block both dopamine agonist and non-competitive NMDA antagonist disruption of PPI is considered a marker for potential atypical antipsychotic activity (Swerdlow and Geyer 1998). Since OLETF rats were resistant to disruption of PPI by both a dopamine agonist and a non-competitive NMDA antagonist, they resemble rats pretreated with an atypical antipsychotic drug. Understanding the neurobiological mechanisms underlying this relative insensitivity in OLETF rats could shed light on the mechanisms underlying genetic vulnerability to PPI deficits and restoration of drug-disrupted PPI. 


\section{ACKNOWLEDGMENTS}

The authors would like to thank Ms. Tammi Reza for her excellent technical assistance. DF and PDS are recipients of grants from the National Alliance For Research on Schizophrenia and Depression. PDS is also supported in part by a Psyhopharmacology Research Fellowship Grant MH18399. We kindly thank Dr. Kazuyuki Kawano of the Tokushima Research Institute, Otsuka Pharmaceutical Com., Ltd., for providing OLETF and LETO rats.

\section{REFERENCES}

Acri JB, Brown KJ, Saah MI, Grunberg NE (1995): Strain and age differences in acoustic startle responses and effects of nicotine in rats. Pharmacol Biochem Behav 50:191198

al-Amin HA, Schwarzkopf SB (1996): Effects of the PCP analog dizocilpine on sensory gating: potential relevance to clinical subtypes of schizophrenia. Bio Psychiatry 40:744-754

Bakshi VP, Geyer MA (1995): Antagonism of phencyclidineinduced deficits in prepulse inhibition by the putative atypical antipsychotic olanzapine. Psychopharmacology 122:198-201

Bakshi VP, Geyer MA (1997): Phencyclidine-induced deficits in prepulse inhibition of startle are blocked by prazosin, an alpha-1 noradrenergic antagonist. J Pharmacol Exp Ther 283:666-674

Bakshi VP, Swerdlow NR, Geyer MA (1994): Clozapine antagonizes phencyclidine-induced deficits in sensorimotor gating of the startle response. J Pharmacol Exp Ther 271:787-794

Braff DL, Geyer M (1990): Sensorimotor gating and schizophrenia: Human and animal model studies. Arch Gen Psych 47:181-188

Crawley J (1991): Cholecystokinin-dopamine interactions. TINS 165:6147-6151

Crawley JN (1992): Subtype-selective cholecystokinin receptor antagonists block cholecystokinin modulation of dopamine-mediated behaviors in the rat mesolimbic pathway. J Neurosci 12:3380-3391

Depoortere R, Perrault G, Sanger DJ (1997): Potentiation of prepulse inhibition of the startle reflex in rats: Pharmacological evaluation of the procedure as a model for detecting antipsychotic activity. Psychopharmacology 132:366-374

Feifel D (1999): Individual differences in prepulse inhibition of startle as a measure of individual dopamine function. Behavior Neurosci 113:1020-1029

Feifel D, Reza T (1999): Oxytocin modulates psychotomimetic-induced deficits in sensorimotor gating. Psychopharmacology 141:93-98

Feifel D, Reza TL, Robeck SL (1999a): Antipsychotic potential of CCK-based treatments: An assessment using the prepulse inhibition model of psychosis. Neuropsychopharmacology 20:141-149

Feifel D, Reza TL, Wustrow DJ, Davis MD (1999b): Novel antipsychotic-like effects on prepulse inhibition of star- tle produced by a neurotensin agonist. J Pharmacol Exp Ther 288:710-713

Feifel D, Swerdlow N (1997): The modulation of sensorimotor gating deficits by mesolimbic cholecystokinin. Neurosci Let 229: 5-8

Fendt M, Koch M, Kungel M, Schnitzler H (1995): Cholecystokinin enhances the acoustic startle response in rats. Neuroreport 6:2081-2084

Funakoshi A, Miyasaka K, Shinozaki H, Masuda M, Kawanami T, Takata Y, Kono A (1995): An animal model of congenital defect of gene expression of cholecystokinin (CCK)-A receptor. Biochem Biophys Res Com 210:787796

Furuya Y, Kagaya T, Ogura H, Nishizawa Y (1999): Competitive NMDA receptor antagonists disrupt prepulse inhibition without reduction of startle amplitude in a dopamine receptor-independent manner in mice. Euro J Pharmacol 364:133-140

Hokfelt T, Skirboll L, Rehfeld JF, Goldstein M, Markey K (1980): A subpopulation of mesencephalic dopamine neurons projecting to limbic areas contain a cholecystokinin-like peptide. Neuroscience 5:2093-2124.

Johansson C, Jackson DM, Svensson L (1997): Nitric oxide synthase inhibition blocks phencyclidine-induced behavioral effects on prepulse inhibition and locomotor activity in the rat. Psychopharmacology 131:167-173

Johansson C, Jackson DM, Zhang J, Svensson L (1995): Prepulse inhibition of acoustic startle, a measure of sensorimotor gating: Effects of antipsychotics and other agents in rats. Pharmacol Biochem Behav 52:649-654

Josselyn S, Frankland P, Petrisano S, Bush D, Yeomans J, Vaccarino F (1995): The CCKB antagonist, L-365,260, attenuates fear-potentiated startle. Peptides 16:13131315

Kariya K, Tanaka J, Nomura M (1994): Systemic administration of CCK-8S, but not CCK-4, enhances dopamine turnover in the posterior nucleus accumbens: A microdialysis study in freely moving rats. Brain Res 657:1-6

Keith VA, Mansbach RS, Geyer MA (1991): Failure of haloperidol to block the effects of phencyclidine and dizocilpine on prepulse inhibition of startle. Biological Psychiatry 30:557-566

Kihara T, Ikeda M, Matsubara K, Matsushita A (1993): Differential effects of ceruletide on amphetamine-induced behaviors and regional dopamine release in the rat. Euro J Pharmacol 230:271-277

Kinney GG, Wilkinson LO, Saywell KL, Tricklebank MD (1999): Rat strain differences in the ability to disrupt sensorimotor gating are limited to the dopaminergic system, specific to prepulse inhibition, and unrelated to changes in startle amplitude or nucleus accumbens dopamine receptor sensitivity. J Neurosci 19:5644-5653

Kobayashi S, Ohta M, Miyasaka K, Funokoshi A (1996): Decrease in exploratory behavior in naturally occurring cholecystokinin (CCK)-A receptor gene knockout rats. Neurosci Let 21:61-64

Logue SF, Owen EH, Rasmussenn DL, Wehner JM (1997): Assessment of locomotor activity, acoustic and tactile startle, and prepulse inhibition of startle in inbred mouse strains and F1 hybrids: implications of genetic 
background for single gene and quantitative trait loci analyses. Neurosci 80:1075-1086

Otsuki M, Akiyama T, Shirohara H, Nakano S, Furumi K, Tachibana I (1995): Loss of sensitivity to cholecystokinin stimulation of isolated pancreatic acini from genetically diabetic rats. Am J Physiol 268:E531-E536

Paylor R, Crawley JN (1997): Inbred strain differences in prepulse inhibition of the mouse startle response. Psychopharmacology 132:169-180

Popoli P, Reggio R, Pèzzola A, Scotti de Carolis A (1995): The stimulation of cholecystokinin receptors in the rostral nucleus accumbens significantly antagonizes the EEG and behavioural effects induced by phencyclidine in rats. Psychopharmacology 120:156-161

Rigdon GC (1990): Differential effects of apomorphine on prepulse inhibition of acoustic startle reflex in two rat strains. Psychopharmacology 102:419-421

Shilling PD, Feifel D, Kelsoe JR (2000): Amphetamineinduced zif268 mRNA expression in the medial posterior nucleus accumbens in cholecystokinin-A receptor mutant rats. Neurosci Let 281:17-20

Sipes TA, Geyer MA (1994): Multiple serotonin receptor subtypes modulate prepulse inhibition of the startle response in rats. Neuropharmacology 33:441-448

Swerdlow NR, Braff D, Taiid N, Geyer MA (1994): Assessing the validity of an animal model of sensorimotor gating deficits in schizophrenia. Arch Gen Psych 51:139-154

Swerdlow NR, Bakshi V, Geyer MA (1996): Seroquel restores sensorimotor gating in phencyclidine-treated rats. J Pharmacol Exp Therap 279:1290-1299

Swerdlow NR, Braff DL, Geyer MA, Koob GF (1986): Central dopamine hyperactivity in rats mimics abnormal acoustic startle response in schizophrenics. Biological Psychiatry 21:23-33

Swerdlow NR, Braff DL, Masten VL, Geyer MA (1990a):
Schizophrenic-like sensorimotor gating abnormalities in rats following dopamine infusion into the nucleus accumbens. Psychopharmacology 101:414-420

Swerdlow NR, Geyer MA (1998): Using an animal model of deficient sensorimotor gating to study the pathophysiology and new treatments of schizophrenia. Schizophrenia Bulletin 24:285-301

Swerdlow NR, Mansbach RS, Geyer MA, Pulvirenti L, Koob GF, Braff DL (1990b): Amphetamine disruption of prepulse inhibition of acoustic startle is reversed by depletion of mesolimbic dopamine. Psychopharmacology 100:413-416

Swerdlow NR, Martinez ZA, Hanlon FM, Platten A, Farid M, Auerbach P, Braff DL, Geyer MA (2000): Toward understanding the biology of a complex phenotype: Rat strain and substrain differences in the sensorimotor gating-disruptive effects of dopamine agonists. J Neurosci 20:4325-436

van Megen HJ, Westenberg HG, den Boer JA, Kahn RS (1996): Cholecystokinin in anxiety. European Neuropsychopharmacology 6:263-280

Varty GB, Higgins GA (1995): Examination of drug-induced and isolation-induced disruption of prepulse inhibition as models to screen antipsychotic drugs. Psychopharmacology 122:15-26

Walker DL, Davis M (1997): Anxiogenic effects of high illumination levels assessed with the acoustic startle response in rats. Biological Psychiatry 42:461-471

Wan FJ, Geyer MA, Swerdlow NR (1995): Presynaptic dopamine-glutamate interactions in the nucleus accumbens regulate sensorimotor gating. Psychopharmacology 120:433-441

Zhang J, Engel JA, Jackson DM, Johansson C, Svensson L (1997): (-)Alprenolol potentiates the disrupting effects of dizocilpine on sensorimotor function in the rat. Psychopharmacology 132:281-288. 